\title{
Digital Comics Exploration on Zhang Daqian Colorful Ink Art Experimental Course
}

\section{Gao Dengming, Qi Yuliang}

Neijiang normal university, Zhang Daqian Academy of Fine Arts, Animation education, 641100

Keywords: Zhang Daqian; Color ink art; Digital cartoon; Experimental course

\begin{abstract}
As a treasure of Chinese culture and art and an important treasure of people's spiritual civilization, Zhang Daqian's color ink art is particularly important in the digital era. The new generation of young college students are the main team in art practice and inheritance. They are constantly shuttling between the Internet and digital creativity, using digital comics to explore the charm of color ink art and depict the story of today. On this premise, Zhang Daqian's experimental course of color ink art pays attention to the cultivation of innovative skills of college students, inherits classic culture and art, applies traditional color ink elements in digital comics, guides college students' innovative practice of color ink comics, and promotes the inheritance and innovation of Daqian's culture and art.
\end{abstract}

\section{The connotation of zhang daqian's color ink art}

Zhang daqian is a renowned master of art both at home and abroad. He explores the techniques of color ink painting and adds new expression methods to Chinese painting; In the west, he traveled to different countries to exchange ideas with masters like Picasso. As a young man, he traveled around the world, studied and accumulated a lot of creative experience, so in his later years, he combined the characteristics of traditional Chinese painting with western modern painting language to explore new color ink art. The connotation of zhang da-qian's color ink art lies in the mutual compatibility and mutual influence of color and ink.

Zhang daqian's technique of color ink, also known as "splashing color and ink", is a kind of difficult painting technique, In color and ink, quantity and degree, form and beauty, virtual and real, need to wear and balance, complementary. The combination of color and ink is also a beautiful encounter between eastern and western art. Western paintings were introduced into China during the Ming and qing dynasties, and began to influence Chinese paintings in the shape, concept and scientific spirit. Based on the traditional "ink painting", the ink-brush painting adds the techniques of applying colors and applying colors in western paintings to make the picture more colorful and bright ${ }^{[1]}$.Zhang daqian color ink art is a perfect integration of ink and color, is a communication and collision of eastern and western art.

\section{Digital comic drawing overview}

Freehand sketch has always been the main way of traditional comic drawing. Nowadays, computer software plays an increasingly important role in drawing comics ${ }^{[3]}$.Digital cartoon is a new style of drawing by using computer drawing software. And by the majority of university young people love and pursue. Digital comics are more diversified than traditional ones, and their color processing is more diversified and controllable. In the digital software can draw a variety of different styles of works, pictures can be saved in digital form, works storage is more convenient and fast. In the experimental course of digital comics, common computer drawing software include Adobe Photoshop, Corel Painter, Sai, etc.

For the convenience of research and practice, in this experiment course of digital comics, the software mainly analyzed and applied is Adobe Photoshop, and the auxiliary drawing tool is digital board. Digital board pressure feeling comfortable, painting the picture color restoration degree, smooth lines.In the aspect of digital comics drawing, Photoshop has a very rich brush, which can 
meet the requirements of drawing comics of different styles. The combination of digital board makes the brush of Photoshop more natural and controllable. When using the digital pen, the author can control the change of line thickness and thickness to satisfy the contrast effect of the scene, and make the picture more expressive and appealing. In addition, Photoshop also has a powerful editing function, which allows you to easily adjust the relationship of the picture. So Photoshop is a great software for drawing digital comics.

\section{The form and characteristic of zhang daqian's color ink art}

\subsection{The form of Color Ink Art}

In order to better let the young college students in the color ink digital cartoon experimental course to use the color ink elements, to guide them to explore the color ink art form. Based on the understanding of color blocks, ink phases, forms and the use of pens, zhang daqian's ink paintings can be divided into three main types: The first point is "ink main color auxiliary", ink painting with color is the subject, color does not affect ink; The second point is "figurative painting with color". In the process of painting with color and ink, the change of water can be controlled to obtain some figurative patterns like "mountain", "thin cloud" and "flowing water". The third point is "image throwing color", which often has uncertainties in painting. In the process of painting, zhang dachan sometimes puts a beautiful color first, and then Outlines the specific shape on the side to imagine again according to the color pattern. To master and understand the form and content of the color ink art before the digital comic drawing has a good foundation for the application of color ink.

\subsection{Application of color ink art and digital comic drawing}

The composition of digital comics drawing is based on painting software, digital board and life experience, and its contents are often composed of feelings from life, inner thinking and spiritual enlightenment. Through the process of painting, the painter gradually presents his own picture of life understanding on the computer painting software. On this premise, zhang daqian's experimental course of color ink art pays attention to the cultivation of innovative skills of college students, inherits classic culture and art, applies traditional color ink elements in digital comics, guides college students' innovative practice of color ink comics, and promotes the inheritance and innovation of daqian's culture and art.

\subsection{Extraction of color ink elements}

In the digital comic drawing, the drawing method refers to the way of traditional Chinese painting landscape, characters, flowers and birds, and then divides the layer to overlay the color ink effect. To retain the basic form of color ink art, directly use copying feeling, mixed with each other to use it in computer comic drawing. The color ink element can be used in different aspects of the content of the painting: the costume of the characters, the background of the picture, the dotted flowers and leaves and trees, etc. Most of the content of color ink art is based on natural beauty. The creator can't build a car behind closed doors. He should cherish his love for everything in the world, feel the great rivers and mountains of the motherland, absorb the essence of the world, appreciate the local culture and customs, and collect inspiration for the creation of color ink art.

\subsection{Key features of color ink language in digital rendering}

Zhang dachan used ink accumulation, ink breaking, color accumulation, color breaking and other methods in a large area in his works, combined the techniques of boneless, splashed ink and large and green in traditional landscape, and absorbed the aesthetic factors of western abstract art and modern art ${ }^{[2]}$.He combines personal emotion with color ink in the picture. The special technique and texture of color ink are transferred to digital cartoon drawing. The pressure of different Chinese brush can be used to create the flowing texture of color ink painting. By changing the transparency of brush, the contrast between the real and the real can be drawn. Zhang's technique is also influenced by his emotion, and zhang's personal emotion and inner activity are closely related in the 
color combination of his color ink art works. In the picture of 《 lushan mountain》, a large amount of ink and blue, stone and green and medium yellow are used in a steady and dignified manner. There are clouds and mist in the mountains, smoke at the bottom of the ravines, jungles on the peaks, and the mountains behind are looming, the picture is magnificent. This painting was painted in the age of zhang da-qian, when zhang da-qian was in the third year of his life, suffering from diseases, but still had the spirit of unyielding in his bones. He resolutely went to mount lushan for artistic creation, and the old master showed great demeanor.

Therefore, in the drawing of digital color ink comics, the matching of colors should conform to the thoughts and feelings when drawing comics. At the same time, zhang da-qian's color ink art emphasizes the diversity and inclusiveness of painting, and does not blindly follow the writing style, but also gets rid of the traditional paradigm of painting and rendering. From the realistic to the freehand, from the abstract to the concrete, color ink art can appear on the picture at the same time. The creation form is not controlled by rules and regulations. The effect is bold, the picture is rich, and the personality is distinctive and has strong personal emotion. The symphonies of color blocks and ink blocks, the fusion of lines and colors, and the enhancement of ink accumulation and color accumulation make the rhythm of life and emotion flourish in the works ${ }^{[1]}$.Digital color ink cartoon drawing works should have a clear painting rhythm, such as the contrast of the virtual background of mountains and rivers and the thin flat painting of characters. Digital painting in color ink art is not only the learning and understanding of painting techniques and painting forms, but also has unique advantages in digital adjustment and reproduction.

\section{Experimental application of color ink comics in the course}

At present, under the guidance of the competent department of education, most universities have clearly put forward the principle of "thick foundation and wide scope" in terms of teaching content and course system construction, combined with the goal of talent cultivation. ${ }^{[5]}$ Education is a new education course, which cultivates digital art talents. Based on the drawing of traditional color ink painting, it keeps innovating to expand the knowledge structure and improve the quality of education. The color ink painting art provides continuous inspiration for the drawing of digital comics, greatly elevates the artistic charm of digital comics, guides students' preliminary understanding of color ink comics, and stimulates students' strong interest in digital color ink comics.

\subsection{Art principle learning}

In the study and practice of experimental courses, the art principle of color ink art is an indispensable theoretical basis. The principle of art includes structure, space and other aspects. Among them, the structure of color ink painting can be divided into physical structure and brush and ink structure. In the structure of pen and ink, the focus of the picture is not the specific image but the creator's inner feelings. The art space principle in the ink painting is the perspective relationship in the picture. The ancients said, "there is no cun in the distant mountains, no waves in the distant water, and no eyes in the distant people", This sentence expounds the relationship between the imaginary and the actual perspective of objects in the color ink painting, which is the relationship between the concentration of ink and brush, color brightness and saturation in the concrete expression. The use of ink and brush for distant objects must be light and elegant.

Color ink art is based on "ink painting". On this basis, color is splashed and colored to enrich and vary the color of the picture. The color of the picture has fluidity. The ink method of color ink painting is to use the role of water and color, resulting in thick, light, dry, wet, deep, shallow different changes. Some concrete things, such as mountains, rivers, flowers, animals and birds, can be painted with the outline of Chinese painting before being splashed with color and ink. In the study of the art principles of color ink painting, students should understand the drawing points of color ink painting, and apply them to the drawing of digital comics. 


\subsection{Analysis of software techniques}

In the experimental operation of combining color ink elements into digital comics, students take the paintbrush tools of Photoshop as the auxiliary tools. You need to create a new layer before you start painting. The layer can clearly distinguish the light and weight of the painting, which is also convenient for editing and coloring. When using the brush tool, you can choose brushes with various functions. In the setting of the brush, you can adjust the size, margin, hardness and other parameters of the brush until the setting is satisfactory. If the detail of the painting process is not as ideal as expected, it can be fine-tuned with other tools, such as deformation, rotation, scaling, etc. This saves time and makes the picture perfect. When a complete painting is finished, the color is too bright or too dark for the whole picture. The "curve" tool can be used to modify the light and shade of the picture. The "curve" tool can also control the tone, and the red, green and blue channels can be separately controlled to modify the warm and cold tone of the picture. The "diffusion" and "splash" functions in "filter" can enhance the effect of freehand brushwork and make the picture more colorful ink style.As shown in figure 2, in the process of painting the castle peak in the picture, First, I set the brush to draw the outline of the mountain with the traditional Chinese brush. Next, create a new layer and overlay the color. Finally, the "blurring" effect in the "filter" function is used to modify the picture. Compared with the traditional Chinese painting of qingshan painted by zhang daqian, the painting of qingshan painted by the drawing software is more concise and clear, but the overall effect is less natural (such as figure 1 and figure 2). Digital cartoon drawing takes less time than traditional hand-drawing, but the effect is not as natural as traditional hand-drawing. Therefore, the author should keep learning and analyzing in the course of digital color ink comics, and apply color ink elements better and more naturally to the drawing of digital comics. With the progress of science and technology, people's painting tools have changed. What has not changed is the painter's painting thinking, performance ability and painting concept ${ }^{[4]}$.

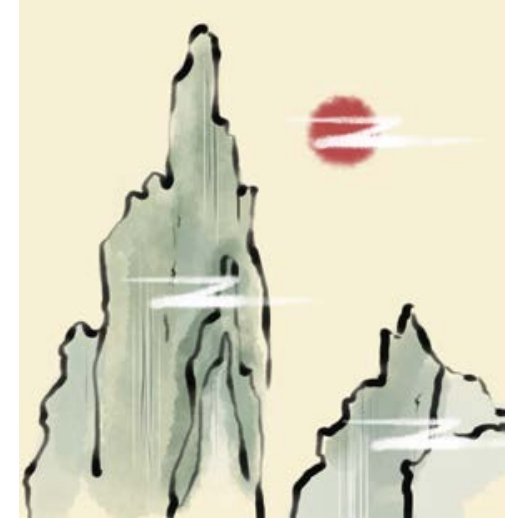

Figure1 Zhang daqian's works

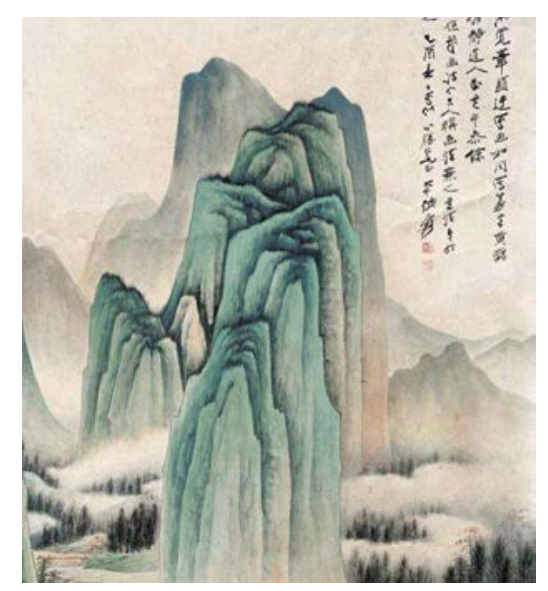

Figure 2 Digital comics case 


\subsection{Comprehensive case training}

As the saying goes, "practice is the only standard to test truth", we need to practice in the experimental course of zhang daqian's color ink digital comics. In the early stage of painting, we should understand the principle of color ink art and master the skills of software drawing. Only by laying these foundations well can we meet the bigger challenge of the drawing process.

It is an essential process of digital painting to train comprehensive cases on the basis of mastering the basic principles. Comprehensive cases can be divided into painting techniques, color use cases, copying cases and other content. Relying on computer drawing software, digital comics is a convenient and quick art form with short production time. With the assistance of advanced science and technology, digital comics art opens up a wider development space. In the study of experimental courses, we should pay attention to practical operation and keep learning and thinking. On the basis of digital comic drawing combined with the characteristics of zhang daqian color ink art, can draw a better digital color ink comics.

\section{Conclusion}

Zhang daqian color ink art is an excellent case of Chinese painting, which brings a lot of inspirations to modern multi-artistic creation. The digital cartoon drawing that integrates the colorful ink art of zhang daqian is a new media art form, which integrates the painting skills of traditional Chinese painting, colorful ink painting techniques of zhang daqian, fashionable and novel digital painting forms, etc., which contains rich cultural connotation.

Zhang daqian color ink art experimental course digital comic drawing, not only to master the drawing software techniques, but also to understand the cultural connotation of color ink art. Only through continuous practice in experimental courses, understanding the creation forms of digital media and combining with traditional art can zhang daqian's excellent painting art be innovatively applied.The color ink digital comics are popular in modern times and originated from ancient times.

Let the color ink art into the university students' art class, so that the traditional culture has a better inheritance and development.

\section{Acknowledgements}

This paper is supported by the following projects, and is one of the project research achievements:

1) Research project of education teaching reform of neijiang normal university: research on the construction path of the experimental course of color ink animation under the teaching mode of "three points", project number: JG201624-339.

2) Students' innovation and entrepreneurship training program of neijiang normal university -"time commemoration -- creation of color ink comics based on life scenes" project no: X2018093

\section{References}

[1] hu yun, compilation and painting. Landscape painting method [M]. Tianjin yangliuqing painting society, 2012.

[2] cao bin. Analysis of the aesthetic characteristics of Chinese landscape painting "ink accumulation" [A]. Journal of lanzhou institute of technology.2014.

[3] liu jing. Comparative study of digital comics and traditional comics [J]. Art education study, 2016 (05): 92-94.

[4] fan lina. Exploration of the method of combining hand-drawing and computer to express the illustration of fashion figures [J]. Art review. 2015(06).

[5] shi he. Reflection on teaching practice of digital painting major [J]. Education theory and practice,2016,36(30):61-62. 